\title{
Frequency of SCA8, SCA10, SCA12, SCA36, FXTAS and $C 9$ orf72 repeat expansions in SCA patients negative for the most common SCA subtypes
}

Gülsah Aydin², Gabriele Dekomien', Sabine Hoffjan', Wanda Maria Gerding ${ }^{1}$, Jörg T. Epplen ${ }^{1,2}$ and Larissa Arning ${ }^{1 *}$ (D)

\begin{abstract}
Background: Spinocerebellar ataxia (SCA) subtypes are often caused by expansions in non-coding regions of genes like SCA8, SCA10, SCA12 and SCA36. Other ataxias are known to be associated with repeat expansions such as fragile $X$-associated tremor ataxia syndrome (FXTAS) or expansions in the C9orf72 gene. When no mutation has been identified in the aforementioned genes next-generation sequencing (NGS)-based diagnostics may also be applied. In order to define an optimal diagnostic strategy, more information about the frequency and phenotypic characteristics of rare repeat expansion disorders associated with ataxia should be at hand.

Methods: We analyzed a consecutive cohort of 440 German unrelated patients with symptoms of cerebellar ataxia, dysarthria and other unspecific symptoms who were referred to our center for SCA diagnostics. They showed alleles in the normal range for the most common SCA subtypes SCA1-3, SCA6, SCA7 and SCA17. These patients were screened for expansions causing SCA8, SCA10, SCA12, SCA36 and FXTAS as well as for the pathogenic hexanucleotide repeat in the C9orf72 gene.

Results: Expanded repeats for SCA10, SCA12 or SCA36 were not identified in the analyzed patients. Five patients showed expanded SCA8 CTA/CTG alleles with 92-129 repeats. One 51-year-old male with unclear dementia symptoms was diagnosed with a large GGGGCC repeat expansion in C9orf72. The analysis of the fragile X mental retardation 1 gene (FMR1) revealed one patient with a premutation (>50 CGG repeats) and seven patients with alleles in the grey zone (41 to 54 CGG repeats).

Conclusions: Altogether five patients showed 92 or more SCA8 CTA/CTG combined repeats. Our results support the assumption that smaller FMR1 gene expansions could be associated with the risk of developing neurological signs. The results do not support genetic testing for C9orf72 expansion in ataxia patients.
\end{abstract}

Keywords: Spinocerebellar ataxia, Repeat expansions, SCA8, Fxtas, C9orf72

\footnotetext{
*Correspondence: larissa.arning@rub.de

'Department of Human Genetics, Ruhr-University, Gebäude MA5/39,

Universitätsstraße 150, 44801 Bochum, Germany

Full list of author information is available at the end of the article
} 


\section{Background}

Autosomal dominant and autosomal recessive inheritance is responsible for the majority of hereditary ataxia subtypes. The spinocerebellar ataxias (SCAs) are autosomal dominantly inherited with a worldwide distribution and an overall prevalence varying from 0.3 to $4.2 / 100000$ [1]. Yet, epidemiological studies that have been conducted on these disorders are relatively rare, and the prevalence estimations vary considerably between countries. Leading symptoms of SCA are cerebellar dysfunctions such as uncoordinated limb movements, unsteady gait, loss of coordination, dysarthria and disturbance of oculomotor control [2]. However, a great variability in the severity and type of symptoms is observed, and the age of onset as well as the rate of disease progression varies between individuals [3]. Up to now, about 35 SCA loci have been mapped and 22 genes have been identified [4]. However, this number is expected to increase in the future, since whole genome or exome sequencing by next-generation sequencing (NGS) offers great potential for finding causative genes of rare subtypes [5]. The high complexity of the clinical picture and the variable genetic background make accurate differential diagnosis often difficult. The most frequent SCA forms are the polyglutamine expansion SCAs that are caused by expanded CAG trinucleotide repeats encoding polyglutamine tracts in various genes [6]. In these cases the repeat expansions can be easily and cost-effectively tested using standard PCR methods. In routine diagnostics the CAG fragment lengths for SCA1, SCA2, SCA3, SCA6, SCA7 and SCA17 are often tested in series. SCA forms that are caused by rare conventional mutations in SCA genes can be tested by Sangerbased DNA sequencing, long time the gold standard for mutation detection [6]. The diagnostic procedure of this gene-by-gene sequencing is cost- and time-consuming, and part of the ataxia patients remain thus without molecular genetic diagnosis. This fact renders difficult to predict a patient's disease progression, to offer effective genetic family counselling and to identify potential novel therapies. Therefore, targeted NGS approaches (gene panels) as well as next-generation whole exome sequencing are becoming more widespread in routine molecular diagnostics for patients with ataxia [7]. However, since NGS at present is not suitable for detecting (trinucleotide) repeat expansions [8], a pre-NGS testing for common polyglutamine expansion SCAs appears mandatory. Further, SCA subtypes caused by expansions in non-coding regions of genes responsible for SCA8, SCA10, SCA12 and SCA36 as well as other ataxias known to be associated with repeat expansions such as fragile X-associated tremor ataxia syndrome (FXTAS) should be taken into account before applying NGS-based diagnostics.

In order to define an optimal diagnostic strategy, more information about the frequency and phenotypic characteristics of rare repeat expansion disorders associated with ataxia would be helpful [9, 10]. We therefore analyzed a cohort of unrelated German 440 patients with symptoms of cerebellar ataxia, dysarthria and other unspecific symptoms who showed alleles in the normal range for the routinely tested SCA types. After screening for expansions in SCA8, SCA10, SCA12, SCA36 and FXTAS, the cohort was additionally evaluated for a pathogenic hexanucleotide repeat in the C9orf2 gene, which has recently been identified as a common pathogenic mutation in families with autosomal dominant frontotemporal dementia (FTD) and amyotrophic lateral sclerosis (ALS) [11]. However, the spectrum of neurological conditions associated with the repeat expansion in C9orf72 is very broad, including rarely cerebellar ataxias [12]. In order to check if C9orf72 expansions also contribute to the spectrum of neurological conditions found in our cohort, we included the screening for C9orf72 expansions in our analyses.

\section{Methods \\ Patients}

We studied a consecutive series of 440 unrelated German patients who were referred to the Department of Human Genetics in Bochum for genetic testing for SCA in the years 2008-2015. They show alleles in the normal range for SCA1, SCA2, SCA3, SCA6, SCA7, and SCA17. SCA diagnosis was requested through clinical neurologists or other specialists. The cohort is clinically heterogeneous, with mild to severe symptoms of cerebellar ataxia, dysarthria and other neurologic symptoms of varying duration. Clinical data and family history were reviewed to the extent available. The study methods were approved by the institutional review board of the Ruhr-University Bochum. Written informed consent for genetic studies was obtained from all patients enrolled in the study.

\section{Molecular testing}

Genomic DNA was extracted from peripheral blood leukocytes using the conventional method. For SCA8, SCA10 and SCA36 triplet repeat primed PCR (TP-PCR) assays based on the method of Warner et al. were performed in order to detect very large expansions that cannot be amplified by PCR-fragment analyses using primer pairs flanking the respective repeat [13]. Patients that appeared homozygous for one allele in the normal fragment analyses were reanalyzed with TP-PCR in order to detect very long pathogenic repeats that could have been missed by conventional PCR [14-16]. In order to analyze the GC-rich C9orf72 hexanucleotide repeat expansions, we applied a flanking and repeat-primed PCR assay according to Cleary et al. [17]. Fragile X mutations were analyzed by conventional fluorescent PCR which is sufficient to detect normal and premutation 
Table 1 Genetic and clinical features as provided from the referring physician of the five patients (two females/ three males) with SCA8 repeat expansions

\begin{tabular}{llllll}
\hline Patient & \multicolumn{2}{l}{$\begin{array}{l}\text { (CTA/CTG)n } \\
\text { allele 1/2 }\end{array}$} & Symptoms & Age at onset & Family history \\
\hline 1 & 22 & 129 & Gait ataxia, dysarthria, atrophy of the cerebellum & $19-21$ & affected mother \\
2 & 26 & 125 & Atrophy of the cerebellum & NA & NA \\
3 & 24 & 122 & Gait ataxia, dysarthria, saccadic eye movements & $19-21$ & no \\
4 & 30 & 116 & Stance and gait ataxia, dysarthria, saccadic eye movements & $45-47$ & no \\
5 & 25 & 92 & Movement disorder, dementia & $41-43$ & no \\
\hline
\end{tabular}

NA not available

alleles and therefore to exclude the diagnosis of Fragile $\mathrm{X}$ syndrome (FXS) due to full mutations. PCR products were separated and analyzed on an ABI 3500XL Genetic Analyzer (Applied Biosystems) and evaluated using the GeneMapper v4.1 software (Applied Biosystems). All primer sequences are available upon request.

\section{Results}

\section{SCA8}

The majority of patients showed SCA8 CTA/CTG combined repeat lengths between 15 and 42. Repeats of 92 or longer were observed in five patients (92-129, Table 1). Patients that appeared homozygous for one allele in the normal fragment range were reanalyzed with fluorescent TP-PCR in order to detect very long pathogenic CTA/CTG repeat blocks [14]. None showed a pathogenic expansion.

\section{SCA10, SCA12, SCA36}

No expanded repeats for SCA10, SCA12 or SCA36 were found in the 440 patients. For SCA10 the number of ATTCT pentanucleotide motifs ranged from 12 to 25 . The most common normal alleles in our German cohort contained 15 or 16 ATTCT repeats. Patients that appeared homozygous were reanalyzed with fluorescent repeatprimed PCR. Normal SCA12 alleles ranged from 9 to 24
CAG repeats, with 10 CAG repeats being most frequent (60\%). For SCA36 the fragment analysis revealed that normal repeats ranged from 5 to 13 GGCCTG repeat units. Extreme GGCCTG repeat expansions were excluded by repeat-primed PCR analysis.

\section{Fxtas}

Analysis of the fragile $\mathrm{X}$ mental retardation 1 gene (FMR1) identified one patient with a premutation above 50 CGG repeats. This female patient with 57 repeats presented at the age of 57 years with slowly progressive stance and gait ataxia and dysarthria. Additionally, seven patients ( 3 males $/ 4$ females) were identified with alleles in the grey zone, ranging in size from 41 to 54 CGG repeats (Table 2).

\section{C9orf72}

The numbers of GGGGCC repeats varied from 2 to 24 units in the normal range (Fig. 1). Analyzing all apparently homozygous patients with fluorescent repeatprimed PCR identified one C9orf72 mutation carrier in our cohort. The patient first appeared as homozygous for a short allele (2 GGGGCC repeat) using the routine assay, but reanalysis with fluorescent TP-PCR showed the typical pattern of an expansion as observed in the positive control.

Table 2 Genetic and clinical features as provided from the referring physician of the eight patients (five females/three males) with FMR1 premutation/alleles in the grey zone

\begin{tabular}{|c|c|c|c|c|c|}
\hline Patient & $\begin{array}{l}\text { (CG } \\
\text { allel }\end{array}$ & $\begin{array}{l}n \\
1 / 2\end{array}$ & Symptoms & Age at onset & Family history \\
\hline | & 30 & 57 & Slowly progressive stance and gait ataxia and dysarthria & $56-58$ & no \\
\hline$\|$ & 53 & & Stance and gait ataxia & NA & no \\
\hline III & 30 & 49 & Unsteady gait with a tendency to fall & NA & no \\
\hline IV & 31 & 47 & Cerebellar ataxia & NA & affected brother \\
\hline V & 30 & 45 & Gait ataxia, dysarthria, nystagmus, diagnosed with fibromyalgia & $59-61$ & no \\
\hline $\mathrm{Vl}$ & 41 & & Progressive gait disturbance, erectile dysfunction, micturition disturbance & NA & no \\
\hline VII & 41 & & Unsteady gait, coordination disturbances of the hands, saccadic eye movements, mild dysarthria & $49-51$ & no \\
\hline VIII & 32 & 41 & Cerebellar ataxia & NA & no \\
\hline
\end{tabular}


C9orf72 allele range

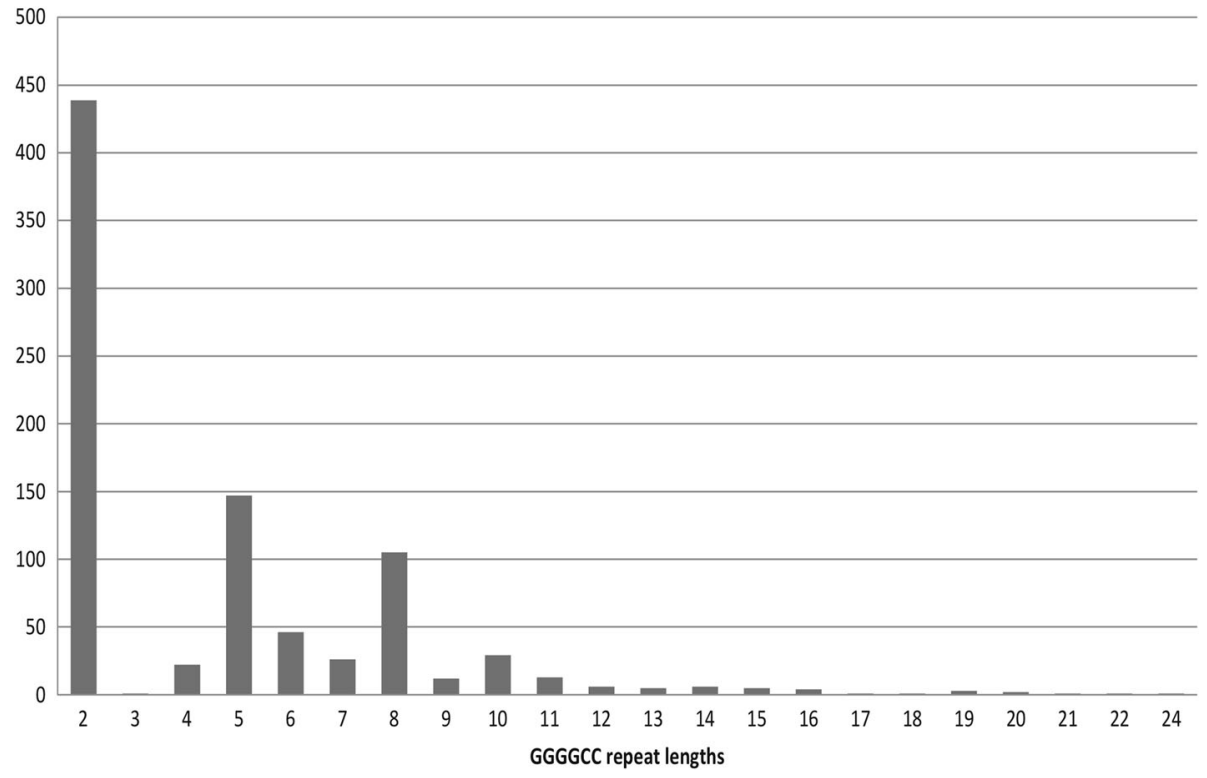

Fig. 1 Distribution of the GGGGCC repeat lengths in the non-expansion carriers

\section{Discussion}

In a first line genetic screening for SCA1, SCA2, SCA3, SCA6, SCA7 and SCA17 mutations 440 ataxia patients were tested negative, as requested through clinical neurologists or other specialists. These unrelated ataxia patients were subsequently assayed for repeat expansions in SCA8, SCA10, SCA12, SCA36, FXTAS and C9orf72.

\section{SCA10, SCA12, SCA36}

No expanded repeats for SCA10, SCA12 or SCA36 were found in this cohort. SCA10 mutations are unstable expansions of a pentanucleotide (ATTCT) repeat in intron 9 of the SCA10 gene. In patients with SCA10 very large expansions of 800 to 4500 ATTCT repeats are found; normal alleles comprise 10 to 22 repeats $[18,19]$. In our German cohort the number of ATTCT pentanucleotide motifs ranges from 12 to 25, with alleles of 15 or 16 ATTCT repeats being most frequent. In support of a founder mutation in the Mexican population, our results substantiate the assumption that SCA10 is a rare cause of ataxia in ethnic populations other than Latin American $[6,18,19]$. SCA12 is associated with a CAG expansion upstream of the transcription start site of the $P P P 2 R 2 B$ gene, encoding a brain-specific regulatory subunit of the protein phosphatase PP2A. CAG repeats in healthy controls range between 7 and 28, and expansions between 46 and 78 triplets have been associated with the disease so far [20]. The unexpanded SCA12 alleles in our cohort ranged from 9 to 24 CAG repeats, with 10 CAG repeats being most frequent in accordance with previous reports [21]. There are similar results for
SCA36, which is caused by a large ( $>650)$ expansion of an intronic GGCCTG repeat in the NOP56 gene [22]. At present, affected families have predominantly been described in Japan, Spain, and France, while no expansions were found in another German cohort [16, 22-24]. In healthy controls the hexanucleotide repeat ranges between 3 and 14 repeat units, with the nine-repeat allele being the most frequent one in Europeans [16, 22-24]. In our cohort the detected GGCCTG repeat alleles ranged between 5 and 13 units, also with the nine-repeat allele being most frequent, while no sample showed a pathogenic pattern.

\section{SCA8}

In SCA8 analysis, expanded lengths are found comparatively frequently for the combined CTA/CTG combined repeat. In 1999 the expansion of an untranslated CTG repeat on chromosome 13q21 was proposed to cause SCA8 [25]. The polymorphic CTG repeat is situated in direct vicinity to a polymorphic CTA sequence (1-21 repeats) whose length is usually quoted in combination with the CTG repeat length. The potentially pathogenic SCA8 alleles associated with symptoms range from 68 to over 300 combined (CTA)n/(CTG)n repeats [26]. In healthy controls more than $99 \%$ show repeat lengths between 16 and 37 combined repeats [25]. However, because expanded alleles were also detected among healthy controls and expansion did not co-segregate with disease in several families, the established SCA8 pathogenic threshold is questionable [26-28]. Common initial symptoms of SCA8 are scanning dysarthria with 
gait instability with disease onset typically occurring in adulthood [29]. We also found a relatively high frequency of expanded SCA8 repeats in our cohort of patients. Altogether five patients (1.14\%) showed repeat sizes of 92 or more combined repeats. The symptoms of the corresponding patients comprise various neurological symptoms (Table 1). Their family histories are almost consistently negative. This is not too surprising when considering, that because of the reduced penetrance of the repeat expansion in SCA8, the most common presentation is a single affected person in a family [29]. Together with reports on the presence of pathogenic repeat lengths in healthy control cohorts and in patients with other identified genetic causes for ataxia, the reduced penetrance led to the assumption that the expanded CTG repeat may be a rare polymorphism which is in linkage disequilibrium with other mutations at the locus associated with SCA8 and/or other factors contribute to the SCA8 phenotype leading to reduced or incomplete penetrance [29]. In this situation, diagnostic testing for SCA8 should be considered when the family history suggests that the symptoms are sporadic or inherited in an autosomal recessive manner. However, diagnostic testing results for SCA8 should be interpreted with caution, especially when used for genetic counseling.

\section{Fxtas}

In 2001 Hageman et al. described five elderly men with a trinucleotide CGG repeat expansion in the premutation range (55 to 200 CGG repeats) in the FMR1 gene. These patients showed late-onset neurological symptoms consisting of progressive action tremor associated with executive function deficits and generalized brain atrophy [30]. Expansions over 200 CGG repeats located in the promoter region of the FMR1 gene (full mutation) generally lead to transcriptional silencing and result in FXS [31]. Expansions in the premutation range are, however, associated with an increased mRNA transcription [32]. FXTAS classically presents with kinetic tremor and cerebellar gait ataxia in elderly male FMR1 premutation carriers, and also female premutation carriers with a milder form of FXTAS have been reported [33, 34]. However, in recent years it became apparent that the FXS associated premutation disorders correlate with a broad spectrum of symptoms that go beyond the clinical picture of FXTAS and the fragile X-associated primary ovarian insufficiency (FXPOI) [35, 36]. Clinical symptoms also include peripheral neuropathy, autonomic dysfunction as well as progressive cognitive decline and diverse neuropsychological problems such as parkinsonism [36]. Because of the heterogeneity of neurological phenotypes in FXTAS, patients are often initially diagnosed with other disorders like SCA or Parkinson disease (PD), suggesting that FXTAS might explain a substantial number of apparently sporadic cases of lateonset ataxia. Previous studies showed that the frequency of FXTAS in patients with movement disorders ranges from 0 to $5 \%$ in different populations [34, 37-41]. Previous published reports of FXTAS have also suggested that woman are far less frequently affected than males, possibly due to the presence of the second X chromosome and random $\mathrm{X}$ inactivation and/or a sex-specific protective effect, perhaps related to estrogen [33].

Smaller FMR1 gene expansions with 45-54 CGG repeats have been designated as gray zone or intermediate alleles due to their lower risk of expansion into a full mutation causing FXS in later generations $[42,43]$. However, the exact boundaries for the intermediate range vary from 34 to 60 CGG repeats [44]. Interestingly, gray zone alleles also show significantly increased transcriptional activity as compared to that observed in common alleles up to 39 CGG [44]. These alleles are associated with various neurological phenotypes, including classical features of PD, with most patients showing asymmetric rest tremor, bradykinesia, and rigidity, but also kinetic tremor and mild gait ataxia or anxiety [45-47]. Therefore, our results add to the growing body of evidence that gray zone alleles are associated with neurological symptoms. It is also interesting to note that we found a higher share of women than men amongst the patients with FMR1 premutations or grey zone alleles. Possibly women are underdiagnosed in the current diagnostic practice for FXTAS, especially when they present with a clinical course that is typical of males with FXTAS.

\section{C9orf72}

Large expansions of a GGGGCC repeat ( $>400$ repeats) located in intron 1 of the C9orf72 gene are associated with familial ALS and FTD [48]. The frequency of the C9orf72 expansion in ALS patients varies. It is remarkably high in Finland and some other regions and infrequent in Asian populations, an observation that supports the theory of a common founder effect $[49,50]$. Over $90 \%$ of the European population show variable C9orf72 repeat lengths between two and ten repeat units [48]. This pattern of distribution was also shown in our cohort (Fig. 1). Besides the strong link to ALS and FTD, which are both heterogeneous diseases, the phenotypic spectrum of C9orf72 expansions extends to other neurodegenerative syndromes such as $\mathrm{PD}$, progressive muscular atrophy (PMA), primary lateral sclerosis (PLS), Huntington-like disease as well as ataxia syndromes [51-54]. The patient diagnosed with a large GGGGCC repeat expansion in our cohort was a 51-yearold man who is described as having unclear dementia syndromes, neurological restrictions and putative early psychiatric problems. However, no ataxia was mentioned. There was a dominant family history of a similar syndrome in his father. Since dementia is the dominant symptom in 
this patient, this case does not broaden the phenotypic spectrum of pathogenic C9orf72 repeat expansions, but it underlines the importance that special attention should be given to patients with dementia referred for molecular diagnostic of various neurodegenerative disorders.

Although our study has multiple strengths, there are also limitations to consider. First, this is a retrospective study; therefore patient data are partially incomplete like history of symptoms, age at onset, family history and exclusion criteria like positive history of alcohol abuse. Another limitation of this study is that there were no healthy controls included.

\section{Conclusion}

Concerning the implications for genetic SCA testing, one can conclude from these data that testing for SCA10, 12 and 36 is not absolutely essential in a German patient cohort. Expanded SCA 8 repeats occur quite frequently, but with regard to its reduced or incomplete penetrance it is difficult to reliably assess the potential consequences of SCA8 expansions on the phenotype. Therefore, it should be critically considered whether this diagnostic should be a fixed component of SCA routine diagnostics. A similar situation exists in evaluation of the FMR1 gray zone or intermediate alleles. Our results support the assumption that smaller FMR1 gene expansions are also associated with the risk of developing neurological signs, in particular also female patients should be considered in the diagnostic practice for FXTAS. Finally, our study does not support genetic testing for C9orf72 expansion in ataxia patients. Further efforts on this field of research are required.

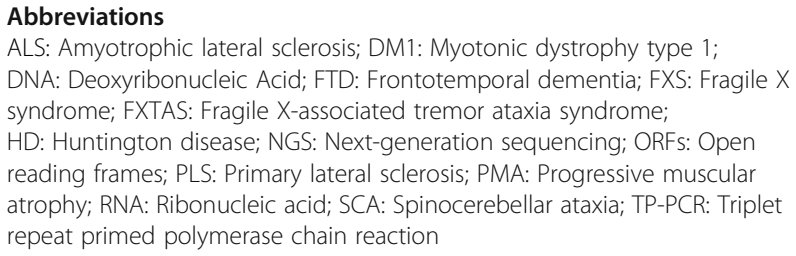

\section{Acknowledgements}

Not applicable

\section{Funding}

We acknowledge support by the DFG Open Access Publication Funds of the Ruhr-Universität Bochum.

\section{Availability of data and materials}

The datasets during and/or analyzed during the current study is available from the corresponding author on reasonable request.

\section{Authors' contributions}

GD, SH, WMG, JTE and LA were involved in designing the study. GA collected the data and conducted the analyses. LA wrote the manuscript. All authors read and approved the final manuscript.

\section{Ethics approval and consent to participate}

All participants gave their informed written consent according to the latest revision of the Declaration of Helsinki. The study has been approved by the responsible ethic committee in Bochum, Germany (Ethik-Kommissionen der Medizinischen Fakultät der Ruhr-Universität Bochum, project number 15-5296).
Consent for publication

Not applicable.

\section{Competing interests}

The authors declare that they have no competing interests.

\section{Publisher's Note}

Springer Nature remains neutral with regard to jurisdictional claims in published maps and institutional affiliations.

\section{Author details}

${ }^{1}$ Department of Human Genetics, Ruhr-University, Gebäude MA5/39, Universitätsstraße 150, 44801 Bochum, Germany. ${ }^{2}$ Faculty of Health, University Witten-Herdecke, Alfred-Herrhausen-Strasse 50, 58448 Witten, Germany.

Received: 22 June 2017 Accepted: 20 December 2017

Published online: 09 January 2018

\section{References}

1. Erichsen AK, Koht J, Stray-Pedersen A, Abdelnoor M, Tallaksen CME. Prevalence of hereditary ataxia and spastic paraplegia in southeast Norway: a population-based study. Brain. 2009;132:1577-88.

2. Schöls L, Amoiridis G, Büttner T, Przuntek H, Epplen JT, Riess O. Autosomal dominant cerebellar ataxia: phenotypic differences in genetically defined subtypes? Ann Neurol. 1997:42:924-32.

3. Manto M-U. The wide spectrum of spinocerebellar ataxias (SCAs). Cerebellum. 2005:4:2-6.

4. Bettencourt C, Ryten M, Forabosco P, Schorge S, Hersheson J, Hardy J, et al. Insights from cerebellar transcriptomic analysis into the pathogenesis of ataxia. JAMA Neurol. 2014;71:831-9. Available from: http://www.pubmed central.nih.gov/articlerender.fcgi?artid=4469030\&tool=pmcentrez\& rendertype=abstract

5. Wang J, Wang JL, Yang $X$, Xia $K, Z M H$, Weng $L$, et al. TGM6 identified as novel causative gene of spinocerebellar ataxias using exome sequencing. Brain. 2010;133:3510-8

6. Durr A. Autosomal dominant cerebellar ataxias: Polyglutamine expansions and beyond. Lancet Neurol. [Internet]. Elsevier Ltd; 2010;9:885-894. Available from: https://doi.org/10.1016/S1474-4422(10)70183-6.

7. Fogel BL, Lee H, Deignan JL, Strom SP, Kantarci S, Wang X, et al. Exome sequencing in the clinical diagnosis of sporadic or familial Cerebellar ataxia. JAMA Neurol. 2014;71:1-10. Available from: http://www.ncbi.nlm.nih.gov/ pubmed/25133958.

8. Singleton $\mathrm{AB}$. Exome sequencing: a transformative technology. Lancet Neurol. 2011:942-6.

9. Brusco A, Cagnoli C, Franco A, Dragone E, Nardacchione A, Grosso E, et al. Analysis of SCA8 and SCA12 loci in 134 Italian ataxic patients negative for SCA1-3, 6 and 7 CAG expansions. J Neurol. 2002;249:923-9.

10. Choubtum L, Witoonpanich $P$, Hanchaiphiboolkul S, Bhidayasiri R, Jitkritsadakul O, Pongpakdee S, et al. Analysis of SCA8, SCA10, SCA12, SCA17 and SCA19 in patients with unknown spinocerebellar ataxia: a Thai multicentre study. BMC Neurol. 2015;15:166. Available from: http://www. pubmedcentral.nih.gov/articlerender.fcgi?artid=4571065\&tool= pmcentrez\&rendertype=abstract.

11. Herdewyn S, Zhao H, Moisse M, Race V, Matthijs G, Reumers J, et al. Wholegenome sequencing reveals a coding non-pathogenic variant tagging a non-coding pathogenic hexanucleotide repeat expansion in C9orf72 as cause of amyotrophic lateral sclerosis. Hum Mol Genet. 2012;21:2412-9.

12. Souza PV, Pinto WB, Oliveira AS. C9orf72-related disorders: expanding the clinical and genetic spectrum of neurodegenerative diseases. Arq Neuropsiquiatr. 2015;73:246-56. Available from: http://www.scielo.br/mwg internal/de5fs23hu73ds/progress?id=ul1kMSFmRFTRrKsmC7KaqZLty 9Uz9vEL2kjLd9AjscQ

13. Warner JP, Barron LH, Goudie D, Kelly K, Dow D, Fitzpatrick DR, et al. A general method for the detection of large CAG repeat expansions by fluorescent PCR. J Med Genet. 1996;33:1022-6. Available from: http://jmg. bmj.com/content/33/12/1022.

14. Tanaka E, Maruyama H, Morino H, Kawakami H. Detection of large expansions in SCA8 using a fluorescent repeat-primed PCR assay. Hiroshima J Med Sci. 2011;60:63-6. 
15. Cagnoli C, Michielotto C, Matsuura T, Ashizawa T, Margolis RL, Holmes SE, et al. Detection of large pathogenic expansions in FRDA1, SCA10, and SCA12 genes using a simple fluorescent repeat-primed PCR assay. J Mol Diagn. American Society for Investigative Pathology and Association for Molecular Pathology; 2004;6:96-100. Available from: http://www.pubmedcentral.nih.gov/articlerender.fcgi?artid=1867469 \&tool=pmcentrez\&rendertype=abstract.

16. Obayashi M, Stevanin G, Synofzik M, Monin ML, Duyckaerts C, Sato N, et al. Spinocerebellar ataxia type 36 exists in diverse populations and can be caused by a short hexanucleotide GGCCTG repeat expansion. J Neurol Neurosurg Psychiatry. 2015;86:986-95. Available from: https://www.ncbi.nlm. nih.gov/pubmed/?term=Spinocerebellar+ataxia+type+36+exists+in+diverse +populations+and+can+be+caused+by+a+short+hexanucleotide+GGCCTG +repeat+expansion.

17. Cleary EM, Pal S, Azam T, Moore DJ, Swingler R, Gorrie G, et al. Improved PCR based methods for detecting C9orf72 hexanucleotide repeat expansions. Mol Cell Probes. Elsevier Ltd; 2016;30:218-224. Available from: http://linkinghub.elsevier.com/retrieve/pii/S0890850816300391.

18. Teive HAG, Munhoz RP, Arruda WO, Raskin S, Werneck LC, Ashizawa T. Spinocerebellar ataxia type 10 - a review. Parkinsonism Relat Disord. 2011: 655-61.

19. Matsuura T, Ranum LPW, Volpini V, Pandolfo M, Sasaki H, Tashiro K, et al. Spinocerebellar ataxia type 10 is rare in populations other than Mexicans. Neurology. 2002;58:983. Available from: http://www.neurology.org/cgi/doi/ 10.1212/WNL.58.6.983.

20. O'Hearn E, Holmes SE, Margolis RL. Spinocerebellar ataxia type 12. Handb Clin Neurol. 2012;103:535-47. Available from: http://www.ncbi.nlm.nih.gov/ pubmed/21827912.

21. Cholfin JA, Sobrido MJ, Perlman S, Pulst SM, Geschwind DH. The SCA12 mutation as a rare cause of spinocerebellar ataxia 161. Arch Neurol. 2001;58:1833-5.

22. Kobayashi H, Abe K, Matsuura $T$, Ikeda $Y$, Hitomi T, Akechi $Y$, et al. Expansion of intronic GGCCTG hexanucleotide repeat in NOP56 causes SCA36, a type of spinocerebellar ataxia accompanied by motor neuron involvement. Am J Hum Genet. 2011;89:121-30. Available from: http://dx.doi.org/10.1016/j.ajhg. 2011.05.015.

23. Figley MD, Thomas A, Gitler AD. Evaluating noncoding nucleotide repeat expansions in amyotrophic lateral sclerosis. Neurobiol Aging. 2014;35(4):936. e1-4.

24. García-Murias M, Quintáns B, Arias M, Seixas Al, Cacheiro P, Tarrío R, et al. "Costa da Morte" ataxia is spinocerebellar ataxia 36: clinical and genetic characterization. Brain. 2012;135:1423-35.

25. Koob MD, Moseley ML, Schut LJ, Benzow K a, Bird TD, Day JW, et al. An untranslated CTG expansion causes a novel form of spinocerebellar ataxia (SCA8). Nat Genet 1999;21:379-384.

26. Stevanin G, Herman A, Dürr A, Jodice C, Frontali M, Agid Y, et al. Are (CTG)n expansions at the SCA8 locus rare polymorphisms? Nat Genet. 2000;24:-213. author reply 215. Available from: http://www.ncbi.nlm.nih. gov/pubmed/10700167.

27. Ikeda Y, Dalton JC, Moseley ML, Gardner KL, Bird TD, Ashizawa T, et al. Spinocerebellar ataxia type 8: molecular genetic comparisons and haplotype analysis of 37 families with ataxia. Am J Hum Genet. 2004;75:3-16.

28. Schöls L, Bauer P, Schmidt T, Schulte T, Riess O. Autosomal dominant cerebellar ataxias: clinical features, genetics, and pathogenesis. Lancet Neurol. 2004;3:291-304

29. Ikeda Y, Daughters RS, Ranum LPW. Bidirectional expression of the SCA8 expansion mutation: one mutation, two genes. Cerebellum. 2008:150-8.

30. Hagerman RJ, Leehey M, Heinrichs W, Tassone F, Wilson R, Hills J, et al. Intention tremor, parkinsonism, and generalized brain atrophy in male carriers of fragile X. Neurology. 2001;57:127-30.

31. Lozano R, Azarang A, Wilaisakditipakorn T, Hagerman RJ. Fragile X syndrome: a review of clinical management. Intractable Rare Dis Res. 2016;5:145-57. Available from: http://www.pubmedcentral.nih.gov/ articlerender.fcgi?artid=4995426\&tool=pmcentrez\&rendertype=abstract.

32. Tassone F, Hagerman RJ, Taylor AK, Gane LW, Godfrey TE, Hagerman PJ. Elevated levels of FMR1 mRNA in carrier males: a new mechanism of involvement in the fragile-X syndrome. Am J Hum Genet. 2000;66:6-15. Available from: http://www.pubmedcentral.nih.gov/articlerender. fcgi? artid=1288349\&tool=pmcentrez\&rendertype=abstract.

33. Hagerman RJ, Leavitt BR, Farzin F, Jacquemont S, Greco CM, Brunberg JA, et al. Fragile-X-associated tremor/ataxia syndrome (FXTAS) in females with the
FMR1 premutation. Am J Hum Genet. 2004;74:1051-6. Available from: http://www.pubmedcentral.nih.gov/articlerender.fcgi?artid=1181968\&tool= pmcentrez\&rendertype=abstract.

34. Zühlke C, Budnik A, Gehlken U, Dalski A, Purmann S, Naumann M, et al. FMR1 premutation as a rare cause of late onset ataxia: evidence for FXTAS in female carriers [8]. J Neurol. 2004;251:1418-9.

35. Hagerman PJ, Hagerman RJ. HHS Public Access. 2016;1338:58-70.

36. Hall DDA, O'keefe JJA. Fragile x-associated tremor ataxia syndrome: the expanding clinical picture, pathophysiology, epidemiology, and update on treatment. Tremor Other Hyperkinet Mov (N Y). 2012;2:1-11. Available from: http://www.ncbi.nlm.nih.gov/pmc/articles/PMC3570061/ \%5Cnhttp://www.pubmedcentral.nih.gov/articlerender.fcgi?artid= $3570061 \&$ tool=pmcentrez\&rendertype $=$ abstract

37. Macpherson J, Waghorn A, Hammans S, Jacobs P. Observation of an excess of fragile- $X$ premutations in a population of males referred with spinocerebellar ataxia. Hum Genet. 2003;112:619-20. Available from: https:// www.ncbi.nlm.nih.gov/pubmed/?term=Observation+of+an+excess+of +fragile-X+premutations+in+a+population+of+males+referred+with +spinocerebellar+ataxia.

38. Brussino A, Gellera C, Saluto A, Mariotti C, Arduino C, Castellotti B, et al. FMR1 gene premutation is a frequent genetic cause of late-onset sporadic cerebellar ataxia. Neurology. 2005;64:145-7. Available from: http://www.ncbi. nlm.nih.gov/pubmed/15642922.

39. Van Esch H, Dom R, Bex D, Salden I, Caeckebeke J, Wibail A, et al. Screening for FMR-1 premutations in 122 older Flemish males presenting with ataxia. Eur J Hum Genet. 2005;13:121-3. Available from: http://www.ncbi.nlm.nih. gov/pubmed/15483640

40. Milunsky JM, Maher TA. Fragile X carrier screening and spinocerebellar ataxia in older males. Am J Med Genet A. 2004;125A:320. Available from: http://www.ncbi.n/m.nih.gov/pubmed/14994246.

41. Seixas Al, Maurer MH, Lin M, Callahan C, Ahuja A, Matsuura T, et al. FXTAS, SCA10, and SCA17 in American patients with movement disorders [1]. Am J Med Genet. 2005;136 A:87-9.

42. Berry-Kravis E, Abrams L, Coffey SM, Hall DA, Greco C, Gane LW, et al. Fragile $X$-associated tremor/ataxia syndrome: clinical features, genetics, and testing guidelines. Mov Disord. 2007:2018-30.

43. Maddalena A, Richards CS, McGinniss MJ, Brothman A, Desnick RJ, Grier $R E$, et al. Technical standards and guidelines for fragile $X$ : the first of a series of disease-specific supplements to the standards and guidelines for clinical genetics Laboratories of the American College of medical genetics. Quality Assurance Subcommittee of the L Genet Med. 2001;3: 200-5. Available from: http://www.pubmedcentral.nih.gov/articlerender. fcgi?artid=3110344\&tool=pmcentrez\&rendertype=abstract.

44. Loesch DZ, Bui QM, Huggins RM, Mitchell RJ, Hagerman RJ, Tassone F. Transcript levels of the intermediate size or grey zone fragile $X$ mental retardation 1 alleles are raised, and correlate with the number of CGG repeats. J Med Genet. 2007:44:200-4

45. Hall DA, Howard K, Hagerman R, Leehey MA. Parkinsonism in FMR1 premutation carriers may be indistinguishable from Parkinson disease. Parkinsonism Relat Disord. 2009;15:156-9.

46. Hall DA. In the gray zone in the fragile $X$ gene: what are the key unanswered clinical and biological questions? Tremor Other Hyperkinet Mov (N Y). 2014:4:208. Available from: http://www.pubmedcentral.nih. gov/articlerender.fcgi?artid=4050171\&tool=pmcentrez\&rendertype $=$ abstract.

47. Kenna HA, Tartter M, Hall SS, Lightbody AA, Nguyen Q, de los Angeles CP, et al. High rates of comorbid depressive and anxiety disorders among women with premutation of the FMR1 gene. Am J Med Genet B Neuropsychiatr Genet. 2013;162B:872-8. Available from: http://www.ncbi. nlm.nih.gov/pubmed/24003006.

48. Renton AE, Majounie E, Waite A, Simón-Sánchez J, Rollinson S, Gibbs JR, et al. A hexanucleotide repeat expansion in C9ORF72 is the cause of chromosome 9p21-linked ALS-FTD. Neuron. 2011;72:257-68.

49. Majounie E, Renton AE, Mok K, Dopper EGP, Waite A, Rollinson S, et al. Frequency of the C9orf72 hexanucleotide repeat expansion in patients with amyotrophic lateral sclerosis and frontotemporal dementia: a cross-sectional study. Lancet Neurol. 2012;11:323-30

50. Konno T, Shiga A, Tsujino A, Sugai A, Kato T, Kanai K, et al. Japanese amyotrophic lateral sclerosis patients with GGGGCC hexanucleotide repeat expansion in C9ORF72. J Neurol Neurosurg Psychiatry. 2012;84:398-401. Available from: http://www.ncbi.nlm.nih.gov/pubmed/23012445. 
51. Lesage S, Le Ber I, Condroyer C, Broussolle E, Gabelle A, Thobois S, et al. C9orf72 repeat expansions are a rare genetic cause of parkinsonism. Brain. 2013;136:385-91.

52. Liu Y, JT Y, Zong Y, Zhou J, Tan L. C9ORF72 mutations in neurodegenerative diseases. Mol Neurobiol. 2014:386-98.

53. Hensman DJ, Poulter M, Beck J, Hehir J, Polke JM, Campbell T, et al. C9orf72 expansions are the most common genetic cause of Huntington disease phenocopies. Neurology. 2014;82:292-9.

54. Corcia P, Vourc'h P, Guennoc A-M, Del Mar AM, Blasco H, Andres C, et al. Pure cerebellar ataxia linked to large C9orf72 repeat expansion. Amyotroph Lateral Scler Front Degener. 2015;8421:1-3.

Submit your next manuscript to BioMed Central and we will help you at every step:

- We accept pre-submission inquiries

- Our selector tool helps you to find the most relevant journal

- We provide round the clock customer support

- Convenient online submission

- Thorough peer review

- Inclusion in PubMed and all major indexing services

- Maximum visibility for your research

Submit your manuscript at www.biomedcentral.com/submit
Biomed Central 